\title{
eEmerald $\begin{gathered}\text { Information Technology } \\ \text { \& People }\end{gathered}$
}

\section{An empirical study of purchase behaviour on social platforms: \\ The role of risk, beliefs and characteristics}

\begin{tabular}{|r|l|}
\hline Journal: & Information Technology \& People \\
\hline Manuscript ID & ITP-08-2017-0267.R2 \\
\hline Manuscript Type: & Article \\
\hline Keywords: & $\begin{array}{l}\text { Social Network Analysis, Gender, Privacy, Information sharing, Security, } \\
\text { Risk < Theoretical concept }\end{array}$ \\
\hline \multicolumn{2}{|l}{} \\
\hline
\end{tabular}




\title{
An empirical study of purchase behaviour on social platforms:
}

\author{
The role of risk, beliefs and characteristics
}

\begin{abstract}
Purpose - Social media users' purchasing behaviour is yet to be fully understood by research. We investigate how purchase intention is affected by social media user traits, cognitive factors (such as perceived control and trust) and individual beliefs, such as risk propensity and trustworthiness.
\end{abstract}

Design/methodology/approach - We propose and empirically test a model of purchase intention on social platforms. Our study of over 500 active social media users finds the links between risk propensity, trust, technical efficacy and perceived control and explores the moderating effect of age and gender.

Findings - Purchase intention on social platforms is influenced by demographic factors, cognitive factors and beliefs. Both age and gender moderate the effects of beliefs and cognitive factors: age is a determinant of purchase intention for men, while beliefs are significant for younger women and cognitive factors are significant for older women.

Research limitations/implications - This study involved a cross-sectional design via online survey of social networking users. Gender differences in purchase intentions are found which are in turn influenced by age. Further empirical testing of social purchase intention could include less experienced users or non-users.

Practical implications - The results of this study provide guidance for SNS providers and technology developers in social networking commerce in terms of the different drivers of purchase intention.

Originality - Social media users' purchasing behaviour is yet to be fully understood. Our study shows that purchase intention antecedents vary between genders and age groups of users. The identified connection between users' perceptions of social networking services (SNS) usage of personal information and purchase behaviour has an impact on the likelihood of user engagement in social transactions. 


\section{INTRODUCTION}

While originally created as a peer-to-peer communication medium, social networks have become a platform for realising commercial opportunities (Im et al. 2008; Miller et al., 2009; Zheng et al., 2015). This has created a variety of implications for information systems research, including how ecommerce and social networks are converging. Social commerce can be regarded as a new dimension of e-commerce in which consumers use Social Networking Sites (SNS) to engage in purchase behaviour (Hajli, 2015).

There are two key business models that are typically used by SNS in this context. The first is where the purchase is routed through the SNS, but does not rely on the network of users to mediate the purchase. In this case the SNS can provide a link to a merchant (usually paid for advertising). The targeting of the advertising is likely to be driven by the users' social media behaviour, but the purchase isn't typically influenced by other users. The closest business model description for these types of transactions is Brokerage, where the SNS acts as an intermediary to the transaction. The second model is where the purchase is influenced by the views of other users (for instance reviews). This second model is typically referred to as Social Commerce. As with any typology there are examples of practices that don't fall neatly under either categories and business models that draw from both 'brokerage' and 'social commerce' including group buying models (Kim, 2013) or the collection of fans and followers.

Brokerage can take many forms on SNS, ranging from helping the customer search for a vendor or a product through to more passive mediation by the SNS such as the display of links on a specific interest group page. It may also help vendors identify groups of potential customers that may have a specific need or a high propensity towards their products or services (Afrasiabi Rad and Benyoucef, 2011). Regardless of the depth of the brokerage and 
the form it actually takes, it is reasonable to assume that the very fact that the brokerage is mediated by the SNS will have an influence on its impact. Purchase behaviour in Social Commerce has distinctive characteristics. Users provide social support for each other via interconnectivity afforded by SNS as such engendering trust into the specific social platform itself or social platforms in general. This interconnection creates opportunities for the cocreation of value by customers and SNS service providers (Hajli, 2014) and opens up business opportunities supported by the business model including Marketing and Sales, Enterprise Management, Knowledge work and Staff recruitment, to name a few (Liang and Turban, 2011).

Many factors underpin the value proposition to customers, both in the 'brokerage' model and the 'social commerce' model used by SNS. Some will be social, some with be technical and others will be at the interface between the two domains (Gorner, Zhang et al., 2013). Going back to ecommerce research is especially useful to understand purchase behaviours in the 'brokerage' model. Purchase behaviour has been explored in depth and shown as significantly associated with control over information, privacy and risk (Brown and Muchira, 2004; Zorotheos and Kafeza, 2009; Basheer and Ibrahim, 2010; Baek and Morimoto, 2012; Tucker, 2012; Ponte et al., 2014). Ponte et al. (2014) found that trust, privacy and risk are among the variables affecting purchase intention. Also, trust perceptions and their influence on purchase have been shown to be related to group (Lowry et al., 2011) and gender differences (Jarvenpaa et al., 1999). Solove (2008) has long contended that difficulties involved in discussions of personal information privacy are amplified by technology, in this case by the move from e-commerce to social technology. Chang et al. (2016) show that purchase intention in ecommerce is affected by security and privacy perceptions and influenced by the perceived benefits of transacting in ecommerce. As 'social commerce' as a model is a relatively new phenomenon, the relationship between user perceptions and 
purchase intention is yet to be fully understood (Dehghani and Tumer, 2015). This is of particular interest in light of the cyber security threats increasingly targeting SNS and the rise of perceived risks associated with purchasing (Dumas, 2013; Coopamootoo and Ashenden, 2011).

This leads to two important research questions: (1) What drives purchase intentions in SNS? and (2) How do these drivers vary in their effects across genders and ages? In order to answer these questions we explore the constructs affecting purchase intention on SNS, namely; perceived ability to control submitted information, risk propensity, personal trust, perception towards site trustworthiness, and technical efficacy of users. In the next sections, we present a review of literature on risk, control and trust behaviours on social platforms and purchase intention. We draw from the literature to then develop the research hypotheses and propose a model of purchase intention on social platforms. This is followed by the methodology section, data analysis and the results interpretation. The paper concludes with a discussion of findings and their implications for theory and practice. Future directions for research conclude the paper.

\section{LITERATURE REVIEW}

\subsection{The transactional SNS paradox}

The advantages offered by SNS in commercial settings are based on the benefits yielded by personal information disclosure (Waters and Ackerman, 2011), enabling personalised experience (a benefit to the customer) and the gathering of market intelligence (a benefit to the retailer). Some warn of the online medium having a detrimental effect on privacy as the public information views are changing (Lessig 2006). In his view technology takes control over personal information eroding the notion of "fair use" of information. This is particularly pertinent for social network sites. Privacy has been one of the pressing aspects 
associated with digital media and social networks in particular (Nissenbaum, 2010). Through the lens of the contextual integrity theory, user behaviour evolves over time and ethical concerns mutate. In the case of SNS, social norms shape the ways users behave, including purchase intention, through the effects on interests and preferences of transacting parties. However, privacy remains the cornerstone of the debate about the ownership of the control over personal information and value/function that users see in the digital medium. Extant research has made great efforts to seek explanations of the reasoning behind individuals withholding or disclosing personal information, explored in detail in the e-commerce context. On the other hand, benefits drawn from the use of SNS by individuals tend to be driven by self-disclosure. In fact, disclosure enables individuals to build and maintain relationships on SNS as they actively disclose and share information about themselves with other members. SNS offer additional value to users; it has been shown that social networkers see three types of benefits of belonging to an SNS: social, hedonic and epistemic (Yiang and Lin, 2014). This explains why information disclosure on SNS is driven by socialisation-related factors, such as the need to belong together (social value), the necessity to interact and peer pressure (Chiu, Hsu, and Wang, 2006; Chang Lee and Kwon, 2008). The intrusive and aggressive nature of commercial data collection has contributed towards a heightened sense of privacy invasion online. Some argue that users have lost control over their personal information, especially on social platforms (Xu and Bélanger, 2013).

Where payment transactions are concerned, SNS are distinct to e-commerce. Their original idea encouraged self-disclosure of personal information, yet when payment transactions take place they require as much confidentiality as possible. Extant research identified five other types of information that are found on SNS including service data, entrusted data, incidental data, behavioural and derived data (Schneier 2010), highlighting that behavioural data is 'the critical part of a social networking site's business model' (p. 8) 
used for targeted and customised advertising and is increasingly sold to third parties.

However, others argue that individuals using SNS are 'uncertain about the consequences of privacy-related behaviours and their own preferences over those consequences' (Acquisti et $a l ., 2015$ p. 509). Social networking sites lack much of the offline social granularity which give rise to many privacy issues (Terranova, 2004). Applications subliminally share users' as well as their connections' information with third parties which allegedly violates standard norms of information flow (Hull et al., 2010). Some believe that SNS users are technology savvy and able to protect their personal information which is accessed and shared by online vendors and third-party companies (Osatuyi, 2015). While users view SNS as the responsible agent in ensuring security, SNS themselves argue that the information security breaches are caused by individual user behaviour (Stuzman et al., 2013).

In trying to understand the paradox identified above we follow prior studies which draw from two bodies of literature and their supporting theoretical frameworks. The first is the literature on technology adoption, the Technology Acceptance Model (TAM) and its extensions (Davis, Bagozzi, and Warshaw 1989; Ajzen, 1985; Fishbein and Ajzen, 1975) based on the Theory of Reasoned Action (TRA) (Ajzen and Fishbein, 1980) and the Theory of Planned Behaviour (TPB) (Conner and Armitage, 1998). This group of theories describe the psychology of user acceptance and bring out key variables pertaining to beliefs and attitudes about technology environments. The second body of literature we draw upon is on the situational cognition of whether to transact (or not). This follows on from the findings that beliefs and attitudes and situation specific cognitive appraisal are the drivers for intention to transact in e-commerce (Pavlou, 2003). Similar conclusions are reached by other researchers indicating that cognitive attitudes significantly affected purchase intention in e-commerce transactions (eg. Chang et al., 2016). 


\subsection{Beliefs and attitudes}

A number of 'user attributes' have been identified as key antecedents of SNS behaviour where privacy was at stake (Ngai, 2015). Drawing on similar theoretical basis, the belief of self-efficacy (a concept related to perceived ease of use) as an independent variable influencing user behaviour (Collignon et al., 2013; Tamjidyamcholo et al., 2013). Our model (see Figure 1), therefore, includes technical efficacy as a key construct, which describes users' belief about their general level of technology aptitude and confidence in computer use. The second user attribute in our model is user's attitude to risk, and risk propensity. According to TRA, beliefs influence attitudes and there is substantial evidence in the literature, such as for information disclosure (see for instance Dhillon and Backhouse, 2001) that perceptions of risk influence behaviour which had been shown as lacking in the SNS context.

The third user attribute we include is trust towards SNS provider. Sociological theories lend themselves to thinking of trust as something that a user feels about a specific SNS or a vendor (Pavlou, 2001). However, trust is something that will be felt towards the general technology environment in SNS. This is an important distinction that leads Lee and Turban (2001) to suggest the need for two factors comprising trust in the e-commerce context. The first is the sociological basis of individual trust and the second is trustworthiness, the perception that users place in the technology provider, linked to the reliability of the medium.

\subsection{Cognitive appraisal factors}

Studies of information security have identified factors appraised by users ahead of sharing confidential information as perceived control of information and perceived risk (Hajli and Lin, 2016). A number of studies have successfully integrated the literature on perceived 
risks with TAM (Featherman and Pavlou, 2003). The argument is that perceived risks will influence, and be influenced by perceived usefulness and perceived ease of use which in turn influence behavioural intentions. Further, in the context of online transactions (Pavlou, 2001; Tucker, 2012), linked perceived risk and behavioural intention. When considered in a specific situation, perceived risks are accounted for by users and balanced against the trust they have in the SNS. Perceived risk and trustworthiness of the service provider are common and interlinked antecedents of purchase intention in most theoretical models of purchase intention that emphasise situational cognition (Gefen, Karahann, and Straub 2003; Pavlou and Gefen, 2004; Lee and Turban, 2001; Kim, Ferrin, and Rao, 2008; Zimmer et al., 2010). Liu and Goodhue (2012) and Yoon (2002) explored online user behaviour and the formation of perceived trustworthiness. Once users decide that a site is trustworthy enough, they then drop trustworthiness as a concern.

As pointed out in the ecommerce literature 'consumer trust is a degree of the risk involved in a situation' (Pavlou 2003). We have therefore included a measure of risk propensity alongside the measures of trust. The formation of trust in e-commerce have been examined in depth (e.g. Corritore, Kracher, and Wiedenbeck, 2003; Dinev and Hart, 2006; Keith et al., 2013), concluding that perceptions of credibility, ease of use and risk play a major role in the formation of consumer trust online, which are influenced by user demographics.

\subsection{The influence of user demographic characteristics in online behaviour: age and} gender differences.

Demographic characteristics have been found to influence technology acceptance and are incorporated in later technology acceptance models such as the Unified Theory of User Acceptance of Information Technology (Venkatesh et al., 2003). Demographic factors have 
been found to influence online purchase behaviour, both directly and as moderators of the effects of other factors. For instance, it has been shown that many online consumers are older in age (Bellman et al., 1999; Donthu and Garcia, 1999; Weiss, 2001). Also, older consumers search for fewer products they purchase as much as the younger customers (Sorce et al., 2005). The continuing increase of the Internet use by older adults establishes this demographics as the new sector of growth for commercial opportunities (Lian and Yen, 2014).

Gender is another factor that affects online purchase behaviour. For example, women find online shopping experiences less satisfying than men and hence, this could affect their purchase behaviour (Rodgers and Harris, 2003). Similarly, it emerged that men make more purchases online than women (Garbarino and Strahilevitz, 2004; Korgaonkar and Wolin, 1999, Slyke et al., 2002). In addition, compared to traditional shoppers, online shoppers are better educated (Swinwyard and Smith, 2003), wealthy and high in computer literacy skills as also supported by (Bellman et al., 1999; Ganesh and Agarwal, 2014).

The study of the demographic variables such as age and gender in social media settings is well documented in literature (Maaz, 2011; Madden, 2012; Ng, 2013). For instance, that introversion and neuroticism is higher among women and as a result, they tend to find Internet and social media services more appealing (Hamburger and Ben-Artzi, 2000). However, such gender effects are not observed among teenage social media users (Gross et al., 2002; Joiner et al., 2005). The purpose for which SNS are used differ between teenage males (entertainment) and females (relational activities) (see e.g. Barker, 2009). Such findings suggest that both gender and age affect social media use but whether gender differences become more prominent during adult years is yet to be explored in depth. 
A further open question, which informs our study, is the extent to which age and gender influence behaviour on commercial social media platforms. Prior research suggests that age differences in social media users are significant; according to recent data from $89 \%$ of social media users are between the ages of 18-29 years Pew Research (2016). Researchers believe that young social media users are vulnerable to online privacy losses and are prone to developing addiction to Internet applications (Patchin and Hinduja, 2006; Christakis and Moreno, 2009). The effects of age on social media user behaviour provides an impetus for further research. This is particularly important for gaining a better understanding of user behaviour on commercial social media platforms across different age groups.

\section{CONCEPTUAL FRAMEWORK}

Further to the exploration of purchase intention in e-commerce settings by Chang et al. (2016) there is a strong rationale to explore purchase intentions on SNS through the lens of cognitive appraisal perspectives. Cognitive factors reflect that SNS users' purchase intentions are influenced by judgements about the vendor. We bring in user beliefs and attitudes affecting purchase intention, which are the factors describing user beliefs affect intentions and therefore behaviour. The hypotheses formation is presented in the section which follows.

\subsection{Hypotheses development.}

According to Dinev et al. (2009) awareness about emergent technology takes central stage in determining users' behavioural intentions. While there is a growing body of research regarding online purchase behaviour; there is a definite lack of validated measures which specifically examine purchase intention in relation to SNS (Landoll et al., 2013). In our study, we were interested in exploring the behaviour of individual users on SNS and how this impacts their intention to purchase through social media platforms. 
A study by (Foxman and Kilcoyne, 1993) uncovered that users constantly assess the value of their personal information. They also evaluate how much control they think they have over it, which has been termed as the 'perceived ability to control submitted information' (Dinev and Hart, 2006). On social media platforms control over information has been associated with how privacy control settings are used to limit third-party access to personal data and how profile tracker plug-ins are used to harvest profile views information (Reyns, 2013). When users perceive they have a reasonable level of control over information submitted to SNS in a purchase transaction, then their SNS information is better protected by SNS and they will be more willing to transact on social media platforms. Based on this argument, we derive our first hypothesis:

\section{H1: Users with higher perceived control over personal information collected by SNS have higher} purchase intention.

Online purchase intention in traditional e-commerce has been explored in-depth in the information systems and marketing literature. An important construct of purchase intention is the level of trust between the vendor and the buyer (Liu et al., 2005; Anderson and Agarwal, 2010). More broadly, trust is seen as a 'behavioural intention or a willingness to depend on another party, coupled with a sense of vulnerability or risk if trust is violated' (GrabnerKräuter and Bitter, 2013:p. 4). In online purchasing, trust is considered the most important factor, even more so than price (Reicheld and Schefter, 2000; Wang et al., 2000). Some research shows transacting online (both commercial and self-disclosure) may be influenced by trust in the vendor (Liu et al., 2005), while other studies highlight that trust is dependent on the level of personalisation afforded by the e-commerce site (Xu et al., 2011). We propose the following hypothesis to test this conclusion in social media settings: 
H2: Those users with higher levels of trust in the SNS have higher purchase intentions on social media platforms.

In information security research, the concept of risk has been central to user behaviour (Dhillon and Backhouse, 2001). Here we focus on the concept of risk propensity, which is an action state that determines how much risk an individual is inclined to take. According to (Cases, 2002) risk propensity depends on sources of risk and online activity is a source of risk to individuals. Risk propensity is associated with the willingness to assume risk (Luhmann, 1988; Mayer et a1., 1995; Rousseau et al., 1998; Sheppard and Sherman, 1998) or "the tendency of a decision maker to take or avoid risks" (Sitkin and Pablo, 1992:p. 12).

According to (Trimpop, 1994) risk propensity represents the action stage that follows the decision to take or avoid risk and is seen by some theorists as the result of attitudes and perceptions influencing individual actions or behaviour (Liu et al., 2005).

By participating in the purchase process on social media platforms, individuals engage in risk taking behaviour such as communication with unknown entities and entering security sensitive information (Whittle et al., 2012). Those who are more prone to risk taking will be at ease transacting on social media platforms. Hence:

\section{H3: Social media users with high risk propensity have higher purchase intention.}

In an online environment, technology artefacts play an important role in the formation of attitudes towards computing systems and service provider (Nickel, 2013). Brown and Muchira (2004) highlight that service providers should offer artifacts to enable customers to appraise their trustworthiness as users entrust vendors with their personal information. Higher trustworthiness into technical capabilities of the service provider has been shown to encourage information disclosure by users. Customers are more likely to provide personal information without fabrication to those service providers they see as trustworthy as they 
believe that the information will be processed and transmitted securely (Grabner-Kraeuter 2002). Use of encryption by online vendors signifies "a safe environment for online transactions" and therefore positively affects behavioural intention (Wakefield, 2013). Trustworthiness of provider has been linked to perceived security of transactions and personal information sharing in the context of online auctions (Barnes and Vidgen 2001). Service providers historically used technical artefacts, such as security notices and third party seals, for legal reasons. As shown by (Coopamootoo and Ashenden, 2011) some of these privacy notices (e.g. privacy policies) are "too legalistic and complicated for end-users to read and understand"(p.316). However, technical capabilities and their third-party assurance have been shown to increase trustworthiness of vendors (Pollach, 2007; Orito et al., 2013). SNS on the contrary have been censured for avoiding engagement with security notices and seals of assurance, while social platforms have been criticised for the lack of security (Michaelides and Hosszú, 2009; Grabner-Kräuter and Bitter, 2013). We therefore set the following hypothesis:

H4: Social media users who regard SNS as more trustworthy have higher purchase intention.

Researchers are gradually gaining an insight into how individual user characteristics, including technical efficacy, influence online behaviour (Burns and Roberts, 2013). Some argue that the technical efficacy of SNS users is associated with the intuitiveness and ease of use of social media platforms. According to Anderson and Agarwal (2010) technical efficacy is an individual's understanding of their personal competencies. Others attribute efficacy to the computer skill set necessary to operate a computer system and software packages (George, 2002). Connolly and Bannister (2006) find that the technical efficacy of users is positively related to trust in technology, but the relationship of efficacy and purchase intention in the social networking context remains unclear. We propose to examine the relationship between technical competency of individuals and purchase intention by means of 
the following hypothesis:

H5: Users with higher technical efficacy have higher purchase intention on SNS.

Demographics (such as age and gender) have been found to influence online purchase intention (Rogers and Harris, 2003; Lowry et al., 2009; Lian and Yen, 2014) and moderate the effects of other drivers of purchase intention. Consequently, we estimate the model for male respondents and for female respondents which will allow any moderating effects of gender and age on the hypothesised relationships to be identified.

In summary, in the current research the authors have chosen five variables: perceived control, risk propensity, trustworthiness in vendor, trustworthiness of technological artefacts, and technical efficacy as independent variables affecting the outcome variable, purchase intention. It can be argued that these variables cover the socio-technical aspects discussed previously by Dhillon and Blackhouse (2001) and Siponen (2005).

Figure 1 represents the proposed research model, along with the expected direction of relationships between the constructs.

\section{$<$ FIGURE 1 GOES ABOUT HERE $>$}

The model depicts the theoretical constructs representing user behaviour on social media, perceptions of risk, trust and control, along with the hypothesised causal associations between the constructs. The following section describes the method of this study.

\section{METHOD AND DATA COLLECTION}

\subsection{Sampling and design}

The research population included social media users with purposeful (nonprobability) sampling and volunteer panels of social platform users were employed to collect data for this study. Our proposed model consists of eight variables: the five constructs 
included in the proposed hypotheses plus three age dummies. Applying a ratio of 15-20 observations per variable (see e.g. Hair et al., 2010) this translates to a minimum sample size of 120-160 observations. As we estimate two models (one for male respondents and one for female respondents) the total minimum sample size is $240-320$.

\section{$<<$ TABLE 1 GOES ABOUT HERE $>>$}

The questionnaire was developed using Qualtrics software, and then administered to the target sample through web postings (e.g. on popular SNS like Facebook, LinkedIn, Twitter, etc.). In the survey invitation, a criterion was imposed to eliminate any non-social media users who might come across the survey's bypassing restrictions. Overall, 769 individuals responded to the survey invitation. Distributed via social networking channels, the eligibility of respondents has been determined by the affirmative answer to the question of SNS usage. However, no restrictions were imposed on the origins of the respondents, therefore yielding a sample that was predominantly Anglophone and European. Incomplete responses have also been eliminated, which yielded 514 usable questionnaires registering a completion rate of $67 \%$.

\subsection{The dependent variable: social purchase intention.}

The social purchase intention $\left(s p i_{\mathrm{i}}\right)$ was measured through a seven-point scale $(1=$ strongly disagree, $7=$ strongly agree), where respondents were asked whether they preferred shopping on SNS, whether they intended or were willing to purchase from SNS in the future or were worried about security when purchasing from an SNS. The items and their sources are shown in table 6 in the appendix.

\subsection{The independent variables.}

The variable, perceived control over personal information (cpi $i_{i}$, was measured using four items: capturing ability to control access, and information released, used and provided. 
As with all of the other independent variables, the responses were measured on a seven-point scale from strongly disagree (1) to strongly agree (7). ${ }^{1}$

The risk propensity variable $\left(r p r_{\mathrm{i}}\right)$ was measured with five items asking respondents about their willingness to take and accept risks. Trust in SNS was measured using three items which covered how much SNSs were trusted by respondents. This is distinct from the trustworthiness of the SNS service provider (which we denote as 'trustworthiness') which covers the technical ability of the SNS to protect itself and its members from hacking or other forms of data interception. Trustworthiness was measured by a further three items.

The final explanatory variable captured respondents' experience and confidence in using computers (user's technical efficacy) and was measured using four items. Reliability measures (Cronbach's alpha, Composite Reliability and Average Variance Extracted) are shown in table 2.

\section{$<<$ TABLE 2 GOES ABOUT HERE $>>$}

We also assess the discriminant validity of our constructs by comparing the square root of the Average Variance Extracted (AVE) with the correlation between the constructs. Following the Formell and Larcker criterion, discriminant validity is established for a construct if the square root of its AVE is greater than its correlation with other constructs. The results are shown in table 3 - all of the square roots of the AVEs are greater than the cross-construct correlations.

\section{$<<$ TABLE 3 GOES ABOUT HERE $>>$}

\subsection{Model formulation}

The model in Figure 1 is estimated using ordinary least squares regression. Given that our model involves a single dependent variable, purchase intention, we adopt a regression

\footnotetext{
${ }^{1}$ Since our study is cross-sectional, changes in perceptions over time cannot be observed. For example, perceptions may change if an individual experiences victimisation. However, this issue goes beyond the scope of this paper.
} 
approach to the analysis rather than e.g. Covariance-Based Structural Equation Modelling (CBSEM) or Partial Least Squares Structural Equation Modelling (PLS_SEM)². This also allows us to incorporate dummy variable coded variables such as age and gender. Validated measures for online behaviour have been applied. Respondents' ages were incorporated into the model through three dummy variables (18-28, 29-38 and 39-48) with the age group 49 and over acting as the base category.

\section{FINDINGS}

\subsection{Regression results}

Regression analysis requires that the residuals (the difference between the predicted and observed values of the dependent variable) are normally distributed and have constant variance (homoscedasticity) and that the independent variables do not overlap with each other (i.e. do not display multicollinearity). Test of these assumptions and the results from the regression analysis are shown in table 4.

\section{$<<$ TABLE 4 GOES ABOUT HERE $>>$}

We find no evidence of non-normally distributed residuals (the skewness and kurtosis values lie within accepted ranges) or any evidence of multicollinearity (the Variance Inflation Factors are all below the standard benchmark of 10) - see e.g. Hair, Black, Babin and Anderson (2010). There is however, some evidence that the residuals are not homoscedastic. Consequently, we used robust Standard Errors to calculate the significance values.

\footnotetext{
${ }^{2}$ Ordinary Least Squares (OLS) regression and PL S-SEM are closely related - a PLS-SEM model with single indicators for each construct is indistinguishable from OLS ( see Gefen et al., 2000 for review of SEM techniques)
} 
Similar to results obtained in studies of e-commerce users (e.g. Hwang, 2010), we find that gender acts as a moderator for social purchase intention. As table 4 shows, antecedents of purchase intention on social media platforms for females differ to those for male users.

The results show that perceptions of exercising control over personal information have a positive and significant effect on purchase intention for female users. Hence, this finding provides partial support for hypothesis 1 . Social media activity results in the generation of vast amounts of information which may be commercially sensitive or considered private. Current research (Bertot et al., 2012) indicates a general lack of understanding by the social networking users regarding the ways in which their information is used by the SNS. When social media users feel assured that they have more control over their personal information, they are more likely to purchase through social media platforms. This is particularly important for female users on SNS.

Our results suggest that trust in the online vendor (e-commerce or social media) is an important factor influencing purchase behaviour. In the full sample model and the female respondent model, trust is significant; in the male model the significance value is just above the $5 \%$ benchmark. Therefore, when social media users perceive that a social networking service can be trusted, they are more likely to transact with the site. Hence, hypothesis 2 is partially supported.

We also found a positive significant relationship between risk propensity and purchase intention for women, but not for men, thus, supporting hypothesis 3 for the female population. This outcome has significant implications for user awareness programmes. SNS should be more transparent about the risks associated with the purchase process in the social 
transaction ecosystem and ensure that appropriate safeguarding measures are in place to protect users' security.

Trustworthiness, has been linked to a single point in an online decision making process (e.g. Liu and Goodhue, 2012) of online user behaviour. However, the results are not clear-cut. We find that trustworthiness of SNS is significant in the full sample, however, for women only it is not significant $(p=0.150)$, while for men it is the significance value is slightly higher than 5\% (0.057). Hence hypothesis 4 is not supported .

Technical efficacy has no significant association with purchase intention and this is true for both genders. However, social media users in our sample already possess a sufficient level of technical skills, which is appropriate for conducting purchases on social media platforms - once a threshold level of experience is reached, further experience may not influence purchase behaviour.

\subsection{Age and gender differences}

The literature (e.g. see Sorce et al., 2005; Barker, 2009), suggests that younger users (18-28) tend to have higher online purchase intentions than older age groups. The results in table 4 however, suggest that the age effect on SNS purchase intention holds more strongly for males than females. Younger (18-28 years old) male users have significantly higher purchase intentions compared to other male age groups. We explore this by estimating our model again for younger and older male and female respondents separately, to identify any potential moderating effects of age and gender on the relationships in figure 1. The results are shown in table 5 . 
Some interesting results emerge for younger female users. For them risk propensity is significant for the younger group (18-28 years old) while control and trust are significant for the 29 and older group. However, in the regressions for the male groups the picture is less clear-cut. For the over 29 male group, trustworthiness would only be significant at the $10 \%$ level. Surprisingly for the younger (under 29 group) males we did not identify significant relationships. It suggests that of the younger male age group there may be other influences which drive their decisions. Therefore this area merits further investigation.

The results of our study confirm that control over personal information matters to women participating in social media transactions. When female social media users feel assured that they have more control over personal information, they are more inclined to purchase through social media platforms.

\section{IMPLICATIONS}

\subsection{Implications for research}

Purchase intention is a key outcome variable for the study of social commerce adoption, yet there is much work to be done still to understand how to measure the construct as well as its antecedents (Friedrich, 2017). Here we have chosen to measure purchase intention with scales derived from the consumer behaviour literature rather than that from the technology acceptance literature which is more commonly used (see e.g. Teh and Ahmed, 2012; Akman and Mishra, 2017). Some studies have used very specific scales asking respondents whether they would be prepared to pay membership or credit card fees (Hajli 2015; Dashti et al. 2016). However, such scales would not work for more general surveys such as that used here. The scale used in this study shows excellent values for Cronbach's alpha, composite reliability and discriminant validity. Such scales have proved very useful so far as consumer 
behaviour online has been linked to three groups of influences (Vazquez and Xu 2009), namely (a) attitudes towards online shopping, (b) motivations and (c) information search. In the context of purchase behaviour on social platforms, the technical capabilities of the platform and its chosen business model for transacting (brokerage, social commerce or a combination of both) will determine the influence level potential of these three groups.

An important implication for research from our work relates to understanding of the antecedents of this construct and in particular the moderating impact of gender. There is a dearth of studies in the context of e-commerce (Van Slyke et al. 2002), let alone SNS (Thompson and Lougheed 2012), on the platforms where there is a social dimension to the purchase decision (Zhang et al. 2014). Our study highlights that gender differences not only do exist, but the way they manifest themselves may differ across age groups. We suggest therefore that studies that investigate gender differences should control for age differences and vice-versa.

\subsection{Implications for practice}

With the rise of commercial opportunities on social networks, it is important to understand purchase behaviour of their users. We investigate how purchase intention is affected by user traits, cognitive factors (such as perceived control and trust) and individual beliefs (such as risk propensity and trustworthiness). Our study carries a number of very important implications for practice. As the number of registered users and the proportion of time spent by people using social media continue to increase year on year, the commercial value of personal information and commercial opportunities on social networks continues to rise. It is only a matter of time before monetisation of social media through transactions reaches prevalent levels. Therefore, this study is very important in understanding social media user behaviour and the impediments to social commerce development. 
A key implication for practice is the difference between gender groups. Our study suggests that the messaging around control over personal information and risks (for instance) may need to be different for women compared to that for men. While it is necessary for SNS vendors to ensure that this messaging is strong, our study suggests that if an SNS is able to target their messaging around the controls it offers over personal information towards women it may have a positive impact by influencing the cognitive factors at play.

Previous studies (e.g. Madden, 2012) have suggested that women pay greater attention than men to privacy issues on social media and that they are more influenced by recommendations (Sia et al., 2009). It may therefore be possible to influence female users' purchase intentions on SNS through peer or recommendation based reassurance about control over personal information.

This further contributes to the understanding of to what extent current theoretical perspectives on user behaviour online explain purchase intentions in application to social media. Findings of this study will help inform development of social media user awareness practices and enhancement of trust formation mechanisms implemented on social networking platforms. Further, the results are important to future researchers and scholars who may wish to test similar relationships in different contexts.

\section{LIMITATIONS}

Despite every effort taken by the researchers to achieve objectivity, our study is not without its limitations. The target population of this study is online social media users. For the sample size, literature recommends approximately 400 participants for a population of over 100,000 (Krejcie and Morgan, 1970; Isaac and Michael, 1995). There is still a dearth of literature on effective sampling frames in social platforms. According to Duffy (2002), unrestricted internet samples, or self-selection may not be reliable. Nevertheless, research 
finding shows that self-selected samples are clearer and more complete than targeted samples (Gosling et al., 2004). We acknowledge that the data used in this research is self-reported. Also, it is conceivable that a different set of results may emerge using a different sampling technique. We therefore offer our proposed model for further empirical testing by researchers. One potential avenue would be to test the model's ability to explain purchase behaviour as opposed to intention. A second avenue would be to explore if the findings hold for other regions of the world.

\section{CONCLUSIONS}

With the proliferation of social media applications across personal and commercial activities, the transactional potential of social platforms is yet to be realised. Through a review of literature, we explored why social media environments are somewhat different than e-commerce and warrant specific attention towards social media users attitude, cognitive appraisal and their purchase intentions. We proposed a theoretical model which explains the relationships between perceived control over information, risk and trust which have an impact on the purchase intentions on social media and found that these relationships differ depending on the age and gender of the social media user. Specifically, we find that for women, perceived control, trust and risk propensity predict purchase intention. These relationships are moderated by age - for younger women risk propensity is significant; for older women perceived control and trust are significant. For men, age is the only significant predictor; younger men are more likely to buy via an SNS than older men are. The implications for practice of the research findings are threefold. We identified that while the role of the individual user in understanding risks is important, it cannot be the only protective measure for safe activity on social networks. The results of this study help enhance the theoretical understanding of the effects of user behaviour on social technologies. 
Our findings provide guidance for SNS providers and technology developers seeking to explore new horizons in social networking commerce. Social media services need to take a lead on individual user information controls and protection in order to convey trust and reduce risks, to realise the potential of social commerce and increase the volume of social media transactions. Further, there is a potential avenue for research exploring the influences on male users and buying via social media platforms, as their behavior and differences between age groups are areas for emerging research.

\section{REFERENCES}

Acquisti, A., Brandimarte, L., and Loewenstein, G. (2015). "Privacy and human behavior in the age of information". Science, Vol. 347 No. 622, pp. 509-514.

Afrasiabi Rad, A. and M. Benyoucef (2011). "A model for understanding social commerce." Journal of Information Systems Applied Research, Vol. 4 No. 2 pp.63.

Akman, I. and A. Mishra (2017). "Factors influencing consumer intention in social commerce adoption." Information Technology \& People Vol. 30, No. 2 pp.356-370.

Ajzen, I., and Fishbein, M. (1980). "Understanding attitudes and predicting social behavior". Upper Saddle River, NY: Prentice-Hall.

Ajzen, I. (1985). "From intentions to action: A theory of planned behavior". In J. Kuhl and J. Beckman (Eds.), Action control: From cognitions to behaviors (pp. 11-39). New York:

Springer.

Anderson, C. L., and Agarwal, R. (2010). "Practicing safe computing: a multimethod empirical examination of home computer user security behavioral intentions. MIS Quarterly, Vol. 34, pp. 613-643.

Baek, T. H., and Morimoto, M. (2012). "Stay away from me“. Journal of Advertising, Vol. 41 No. 1, pp. 59-76.

Barker, V. (2009). “Older adolescents' motivations for social network site use: The influence of gender, group identity, and collective self-esteem“. CyberPsychology and Behavior, Vol. 12 No. 2, pp. 209-213.

Basheer, A. M. A-A., and Ibrahim, A. M. A. (2010). "Mobile marketing: Examining the impact of trust, privacy concern and consumers' attitudes on intention to purchase“.

International Journal of Business, Vol. 5 No. 3, pp. 28-41.

Bellman, S., Lohse, G. L., and Johnson, E. J. (1999). "Predictors of online buying behavior". Communications of the ACM, Vol. 4 No. 12, pp. 32-38. 
Bertot, J. C., Jaeger, P. T., and Hansen, D. (2012). “The impact of polices on government social media use: issues, challenges, and recommendations". Government Information Quarterly, Vol. 29 No. 1, pp. 30-40.

Brown, M., and Muchira, R. (2004). "Investigating the relationship between Internet privacy concerns and online purchase behaviour". Journal of Electronic Commerce Research, Vol. 5 No. 1, pp. 62-70.

Burns, S., and Roberts, L. (2013). "Applying the theory of planned behaviour to predicting online safety behaviour". Crime Prevention and Community Safety, Vol. 15, pp. 48-64.

Cases, A. S. (2002). "Perceived risk and risk-reduction strategies in Internet shopping". International Review of Retail, Distribution and Consumer Research, Vol. 12, pp. 375-394.

Chang, S-H, Chih, W.-H., Liou, D. and Yang, Y.-T , (2016),"The mediation of cognitive attitude for online shopping", Information Technology \& People, Vol. 29 No. 3 pp. 618 - 646

Chang Lee, K., and Kwon, S. (2008). "Online shopping recommendation mechanism and its influence on consumer decisions and behaviors: A causal map approach". Expert Systems with Applications, Vol. 35, No. 4, pp. 1567-1574.

Chiu, C., Hsu, M., and Wang, E. (2006). "Understanding knowledge sharing in virtual communities: An integration of social capital and social cognitive theories". Decision Support Systems, Vol. 42, No. 3, pp. 1872-1888.

Christakis, D. A., and Moreno, M. A. (2009). "Trapped in the net: will internet addiction become a $21^{\text {st }}$ century epidemic? "Archives of Pediatrics and Adolescent Medicine, Vol. 163, No. 10, pp. $959-960$.

Collignon, S. E., James, T. L., Warkentin, M., and Kim, B. C. (2013). "What drives perceptions of threats to your Facebook friends' information? "Eighth Annual Symposium on Information Assurance (ASIA'13), Albany, NY, 1-6.

Conner, M., and Armitage, C. J. (1998). "Extending the theory of planned behaviour: A review and avenues for further research“. Journal of Applied Social Psychology, Vol. 28, No. 15, pp. 1429-1464.

Connolly, R., and Bannister, F. (2006). "Factors influencing Irish consumers' trust in Internet shopping“". Journal of Information Technology, Vol. 22, pp. 102-118.

Coopamootoo, P. L., and Ashenden, D. (2011). "Designing usable online privacy mechanisms: What can we learn from real world behaviour? " In A. J. Turner (Ed.), Privacy and identity management for life (pp. 311-324). Heidelberg: Springer.

Corritore, C. L., Kracher, B., and Wiedenbeck, S. (2003). "On-line trust: concepts, evolving themes, a model”. International Journal of Human-Computer Studies, Vol. 58, No. 6, pp. $737-758$.

Culnan, M. J., McHugh, P. J., and Zubillaga, J. I. (2010). "How large US companies can use Twitter and other social media to gain business value“. MIS Quarterly Executive, Vol. 9, No. 4, pp. 243-259. 
Dashti, M., A. Sanayei, H. R. Dolatabadi and M. H. Moshrefjavadi (2016). "An Analysis of Factors Affecting Intention to Purchase Products and Services in Social Commerce." Modern Applied Science Vol, 10 No 12 pp 98.

Davis, F. D., Bagozzi, R. P., and Warshaw, P. R. (1989). "User acceptance of computer technology: a comparison of two theoretical models". Management Science, Vol. 35, No. 8, pp. 982-1003.

Dehghani, M., and Tumer, M. (2015). "A research on effectiveness of Facebook advertising on enhancing purchase intention of consumers". Computers in Human Behavior, Vol. 49, pp. 597-600.

Dhami, A., Agarwal, N., Chakraborty, T. K., Singh, B. P., and Minj, J. (2013). "Impact of trust, security and privacy concerns in social networking: An exploratory study to understand the pattern of information revelation in Facebook. " Proceedings of third International Conference on Advance Computing, IEEE (2013), 465-469.

Dhillon, G., and Backhouse, J. (2001). "Current directions in IS security research: Towards socio-organizational perspectives“. Information Systems Journal, Vol. 11, pp. 127-153.

Dinev, T., Goo, J., Hu, Q., and Nam, K. (2006). "User behaviour towards protective information technologies: the role of national cultural differences". Information Systems Journal, Vol. 19, pp. 391-412.

Dinev, T., and Hart, P. (2006). "An extended privacy calculus model for e-commerce transactions“. Information Systems Research, Vol. 17, No. 1, pp. 61-80.

Donthu, N., and Garcia, A. (1999). "The Internet shopper". Journal of Advertising Research, Vol. 39, No. 3, pp. 52-58.

Dumas, M. B. (2013). "Diving into the Bitstream: Information Technology meets society in a digital world“. UK: Routledge.

Duffy, M. E. (2002) 'Methodological issues in web-based research', Journal of Nursing Scholarship. Wiley Online Library, 34(1), pp. 83-88.

Fishbein, M., and Ajzen, I. (1975). "Belief, attitude, intention and behavior: An introduction to theory and research". Reading: Addison-Wesley.

Foxman, E. R., and Kilcoyne, P. (1993) "Information technology, marketing practice, and consumer privacy: ethical issues". Journal of Public Policy and Marketing, Vol. 12, pp. 106119.

Ganesh, L., and Agarwal, V. (2014). "E-shopping: An extended technology innovation“. Journal of Research in Marketing, Vol. 2, No. 1, pp. 119-126.

Garbarino, E., and Strahilevitz, M. (2004). "Gender differences in the perceived risk of buying online and the effects of receiving a site recommendation". Journal of Business Research, Vol. 57, pp. 768-775. 
Gefen, D., Straub, D, Boudreau, M.-C. (2000). "Structural equation modelling and regression: Guidelines for research practice." Communications of the AIS, Vol. 4, No. 2 pp.179.

George, J. F. (2002). "Influences on the intent to make Internet purchases". Internet Research, Vol. 12, pp. 165-180.

Gosling, S. D., \& Vazire, S., Srivastava, S., \& John, O. P. (2004). "Should we trust Webbased studies? A comparative analysis of six preconceptions about Internet questionnaires". American Psychologist, 59, pp. 93-104.

in online social networks: A multifaceted perspective“. Forum for Social Economics, pp.121.

Gross, E. F., Juvonen, J., and Gable, S. L. (2002). “ Internet use and well-being in adolescence“. Journal of Social Issues, Vol.58, pp.75-90.

Gorner, J., J. Zhang and R. Cohen (2013). "Improving trust modeling through the limit of advisor network size and use of referrals." Electronic Commerce Research and Applications Vol. 12 No. 2, pp. 112-123.

Hair, J., Black, W., Babin, B., and Anderson, R. (2010). "Multivariate data analysis: A global perspective“. Upper Saddle River, NJ: Pearson.

Hajli, N. (2014). "The role of social support on relationship quality and social commerce”. Technological Forecasting and Social Change, 87, 17-27.

Hajli, N. (2015). "Social commerce constructs and consumer's intention to buy”. International Journal of Information Management, 35(2), 183-191.

Hamburger, Y. A., and Ben-Artzi, E. (2000). "The relationship between extraversion and neuroticism and the different uses of the Internet". Computers in Human Behavior, Vol. 16, pp. 441-449.

Hull, G., Lipford, R. \& Latulipe, C. (2010) Contextual gaps: privacy issues on Facebook. Ethics and Information Technology, Vol. 13, pp. 203-243.

Hwang, Y. (2010) "The moderating effects of gender on e-commerce systems adoption factors: an empirical investigation”, Computers in Human Behavior, 26(6), 1753-1760.

Im, S., Lee, D-H., Taylor, C. R., and D'orazio, C. (2008). “The influence of consumer selfdisclosure on web sites on advertising response“. Journal of Interactive Advertising, Vol. 9 , No 1, pp. 87-106.

Isaac, S. and Michael, W. B. (1995) "Handbook in research and evaluation: A collection of principles, methods, and strategies useful in the planning, design, and evaluation of studies in education and the behavioral sciences". Edits publishers.

Jarvenpaa, S. L., Tractinsky, N., and Saarinen, L. (1999). "Consumer trust in an Internet store: A cross-cultural validation“. Journal of Computer-Mediated Communication, Vol. 5, No. 2. http://dx.doi.org/10.1111/j.1083-6101.1999.tb00337.x 
Joiner, R., Gavin, J., Duffield, J., Brosnan, M., Crook, C., Durndell, A., and Lovatt, P. (2005). "Gender, Internet identification, and Internet anxiety: Correlates of Internet use". CyberPsychology and Behavior, Vol. 8, No. 4, pp. 371-378.

Keith, M., Thompson, S., Hale, J., Lowry, P. B., and Greer, C. (2013). "Information disclosure on mobile devices: Re-examining privacy calculus with actual user behavior". International Journal of Human-Computer Studies, Vol. 71, No. 12, pp.1163-1173.

Kim, D. (2013). "Under what conditions will social commerce business models survive?" Electronic Commerce Research and Applications 12(2): 69-77.

Komatsu, A. A (2013). " Study using TAM on the recognition of individuals' privacy and the acceptance of risk". Human aspects of information security, privacy, and trust (pp. 119-126). Heidelberg: Springer.

Komiak, S. Y. X., Benbasat, I., and Wang, W. (2005). "Trust building in virtual salespersons versus in human salespersons: similarities and differences". E-Service Journal, Vol. 3, No. 3, pp. 49-63.

Korgaonkar, P. and Wolin, L. (1999). "A multivariate analysis of web usage". Journal of Advertising Research, pp. 53-68.

Kozinets, R. V. (2002). "The field behind the screen: using netnography for marketing research in online communities. Journal of Marketing Research, Vol. 39, No.1, pp. 61-72.

Krejcie, R. V and Morgan, D. W. (1970) 'Determining sample size for research activities', Educational and psychological measurement. Sage publications Sage CA: Los Angeles, CA, 30 (3), pp. 607-610

Landoll, R. R., La Greca, A. M., and Lai, B. S. (2013). “Aversive peer experiences on social networking sites: development of the social networking-peer experiences questionnaire (SNPEQ) “. Journal of Research on Adolescence, Vol. 23, pp. 695-705.

Lee, H., Lim, D., Kim, H., Zo, H., and Ciganek, A. P. (2015). “Compensation paradox: the influence of monetary rewards on user behaviour". Behaviour and Information Technology, Vol. 34, No. 1, pp. 45-56.

Lee, M. K. O., and Turban, E. (2001). "A trust model for consumer Internet shopping“. International Journal of Electronic Commerce. Vol. 6, No. 1, pp.75-91.

Lessig, L. (2006) "Re-crafting a Public Domain," Yale Journal of Law \& the Humanities: Vol. 18, No. 3 , Article 4, pp 56-83.

Lian, J. W., and Yen, D. C. (2014). "Online shopping drivers and barriers for older adults: Age and gender differences“. Computers in Human Behavior, Vol. 37, pp. 133-143.

Liang, T.-P. and E. Turban (2011). "Introduction to the special issue social commerce: a research framework for social commerce." International Journal of Electronic Commerce 16(2): 5-14. 
Liu, C., Marchewka, J. T., Lu, J., and Yu, C. S. (2005). "Beyond concern - a privacy-trust behavioral intention model of electronic commerce". Information and Management, Vol. 42, No. 2, pp. 289-304.

Liu, B. Q., and Goodhue, D. L. (2012). "Two worlds of trust for potential e-commerce users: Humans as cognitive misers“. Information Systems Research, Vol. 23, No. 4, pp. 1246-1262.

Lowry, P. B., Zhang, D., Zhou, L., and Fu, X. (2009). "Effects of culture, social presence, and group composition on trust in technology-supported decision-making groups“. Information Systems Journal, Vol. 20, No. 3, pp. 297-315.

Lowry, P. B., Cao, J., and Everard, A. (2011). "Privacy concerns versus desire for interpersonal awareness in driving the use of self-disclosure technologies: the case of instant messaging in two cultures“. Journal of Management Information Systems, Vol. 27, No. 4, 163-200. http://dx.doi.org/10.2753/mis0742-1222270406.

Luhmann, N. (1988). "Familiarity, confidence, trust: problems and alternatives". In D. G. Gambetta (Ed.), Trust: Making and breaking cooperative relations (pp. 94-107). New York, NY: Blackwell.

Maaz, W. (2011). "The elderly and the Internet: How senior citizens deal with online privacy“. In S. Trepte and L. Reinecke (Eds.), Privacy online: Perspectives on privacy and self-disclosure in the social web (pp. 235-250). Springer.

Madden, M. (2012). "Privacy management on social media sites". Pew Internet Report 2012: pp. 1-20.

Mayer, R. C., Davis, J. H., and Schoorman, F. D. (1995). “An integrative model of organizational trust". Academy of Management Review, Vol. 20, pp. 709-734.

Miller, K. D., Fabian, F., and Lin S-J. (2009). "Strategies for online communities". Strategic Management Journal, Vol. 30, No. 3, pp. 305-322.

Ng, C. S. P. (2013). "Intention to purchase on social commerce websites across cultures: A cross-regional study“. Information and Management, Vol. 50, pp. 609-620.

Nickel, P. J. (2011). "Trust in technological systems". In M. J. De Vries, S. O. Hansson and A. W. M. Meijers (Eds.), Norms in technology (pp. 223-237). Philosophy of Engineering and Technology. Netherlands: Springer.

Nissenbaum, H. (2010) "Privacy in Context: Technology, Policy and the Integrity of Social Life", Palo Alto CA: Stanford University Press.

Osatuyi, B. (2015). " Is lurking an anxiety-masking strategy on social media sites? The effects of lurking and computer anxiety on explaining information privacy concern on social media platforms“. Computers in Human Behavior, Vol. 49, pp. 324-332.

Patchin, J. W., and Hinduja, S. (2006). "Bullies move beyond the schoolyard: a preliminary look at cyberbullying“. Youth Violence Juvenile Justice, Vol. 4, No. 2, pp. 148-169. 
Pavlou, P. A. (2001). "Integrating trust in electronic commerce with the technology acceptance model: model development and validation". Proceedings of the American conference on Information Systems (AMCIS) (2001), Paper 159.

Pavlou, P. A. (2003). "Consumer acceptance of electronic commerce: integrating trust and risk with the technology acceptance model“". International Journal of Electronic Commerce, Vol. 7, No. 3, pp. 101-134.

Pew Research. (2014) "Social Networking Fact Sheet". January, 2014. Available at: http://www.pewinternet.org/fact-sheets/social-networking-fact-sheet/ [Accessed on 22/07/2015]

Ponte, E. B., Carvajal-Trujillo, E., and Escobar-Rodriguez, T. (2014). "Influence of trust and perceived value on the intention to purchase travel online: Integrating the effects of assurance on trust antecedents“. Tourism Management, Vol. 47, pp. 286-302.

Ranganathan, C., and Ganapathy, S. (2002). "Key dimensions of business-to-consumer web sites“. Information and Management, Vol. 39, No. 6, pp. 457-465.

Reicheld, F. F. and Schefter, P. (2005). "E-loyalty". Harvard Business Review, Vol. 78, No. 4, pp. 105-113.

Reyns, B. W. (2013). "Online routines and identity theft victimisation: further expanding routine activity theory beyond direct-contact offenses". Journal of Research in Crime and Delinquency, Vol. 50, pp. 216-238.

Rogers, S., and Harris, M. A. (2003). "Gender and e-commerce: an exploratory study". Journal of Advertising Research, Vol. 43, No. 3, pp. 322-329.

Rousseau, D. M., Sitkin, S. B., Burt, R. S., and Camerer, C. (1998). "Not so different after all: a cross-discipline view of trust". Academy of Management Review, Vol. 23, pp. 393-404.

Schneier, B. (2010). "A taxonomy of social networking data". Security and Privacy IEEE, Vol. 8, No. 4, pp. 88-108.

Sheppard, B. H., and Sherman, D. M. (1998). "The grammars of trust: a model and general implications“. Academy of Management Review, Vol. 23, pp. 422-437.

Sia, Choon Ling., Lim, Kai H., Leung, Kwok., Lee, Matthew K. O., Huang, W. W., and Benbasat, Izak. (2009). "Web strategies to promote Internet shopping: Is culturalcustomization needed? “ MIS Quarterly, Vol. 33, No. 3, pp. 491-512.

Sitkin, S. B., and Pablo, A. L. (1995). "Reconceptualizing the determinants of risk behaviour". Academy of Management Review, Vol. 17, pp. 9-38.Solove, D. (2008) "Understanding Privacy". Harvard University Press, p 272.

Sorce, P., Perotti, V., and Widrick, S. (2005). "Attitude and age differences in online buying“. International Journal of Retail and Distribution Management, Vol. 33, No. 2, pp. $122-132$.

Sztompka, P. (1999). "Trust: A sociological theory". Cambridge: Cambridge University Press. 
Tamjidyamcholo, A., Bin Baba, M. S., Tamjid, H., and Gholipour, R. (2013). "Information security-professional perceptions of knowledge-sharing intention under self-efficacy, trust, reciprocity, and shared-language“. Computers and Education, Vol. 68, pp. 223-232.

Teh, P.-L. and P. K. Ahmed (2012). Understanding social commerce adoption: An extension of the Technology Acceptance Model. Management of Innovation and Technology (ICMIT), 2012 IEEE International Conference on, IEEE.

Thompson, S. H. and E. Lougheed (2012). "Frazzled by Facebook? An exploratory study of gender differences in social network communication among undergraduate men and women." College Student Journal Vol. 46(1): pp. 88-99.

Terranova, T. (2004) "Network culture: Politics for the information age". London: Pluto Press.

Trimpop, R. (1994). "The psychology of risk taking behaviour". Netherlands: ElsevierScience.

Tucker, C. E. (2012). "The economics of advertising and privacy“. International Journal of Industrial Organization, Vol. 30, No. 3, pp. 326-329.

Vazquez, D. and X. Xu (2009). "Investigating linkages between online purchase behaviour variables." International Journal of Retail \& Distribution Management Vol. 37(5): pp.408419.

Wang, F., Head, M., and Archer, N. (2000). "A relationship-building model for the Web retail marketplace“. Internet Research: Electronic Networking Applications and Policy, Vol. 10, No. 5, pp. 297-308.

Waters, S., and Ackerman, J. (2011). "Exploring Privacy Management on Facebook: Motivations and Perceived Consequences of Voluntary Disclosure“. Journal of ComputerMediated Communication, Vol. 17, pp. 101-115. http://dx.doi.org/10.1111/j.10836101.2011.01559.x

Whittle, H., Hamilton-Giachritsis, C., Beech, A., and Collings, G. (2012). “A review of online grooming: characteristics and concerns". Aggression and Violent Behavior, Vol. 18, No. 1, pp. 62-70.

Weiss, M. J. (2001). "Online America“. American Demographics, Vol. 23, No. 3, pp. 53-56.

Xu, H., and Bélanger, F. (2013). "Information systems journal special issue on: Reframing privacy in a networked world“. Information Systems Journal, Vol. 23, pp. 371-375.

Xu, H., Dinev, T., Smith, J., and Hart, P. (2011). "Information privacy concerns: linking individual perceptions with institutional privacy assurances". Journal of the Association for Information Systems, Vol. 12, No. 12, pp. 798-824.

Yiang, H., and Lin, C. (2014). "Why do people stick to Facebook web site? A value theorybased view“. Information Technology and People, Vol. 27, No. 1, pp. 21-37.

Yoon, S. (2002). "The antecedents and consequences of trust in online-purchase decisions". Journal of Interactive Marketing, Vol. 16, No. 2, pp. 47-63. 
Zhang, K. Z., C. M. Cheung and M. K. Lee (2014). "Examining the moderating effect of inconsistent reviews and its gender differences on consumers' online shopping decision." International Journal of Information Management Vol. 34(2) pp. 89-98.

Zheng, X, Cheung, C., Lee , M, and Liang, L. (2015) "Building brand loyalty through user engagement in online brand communities in social networking sites", Information Technology and People, Vol. 28 No: 1, pp.90 - 106

Zorotheos A., and Kafeza E. (2009). "Users' perceptions on privacy and their intention to transact online: study on Greek internet users". Direct Marketing International Journal, Vol. 3, No. 2, pp. 139-153.

\section{Appendix}


Figure 1. Proposed Model of Social Purchase Intention.

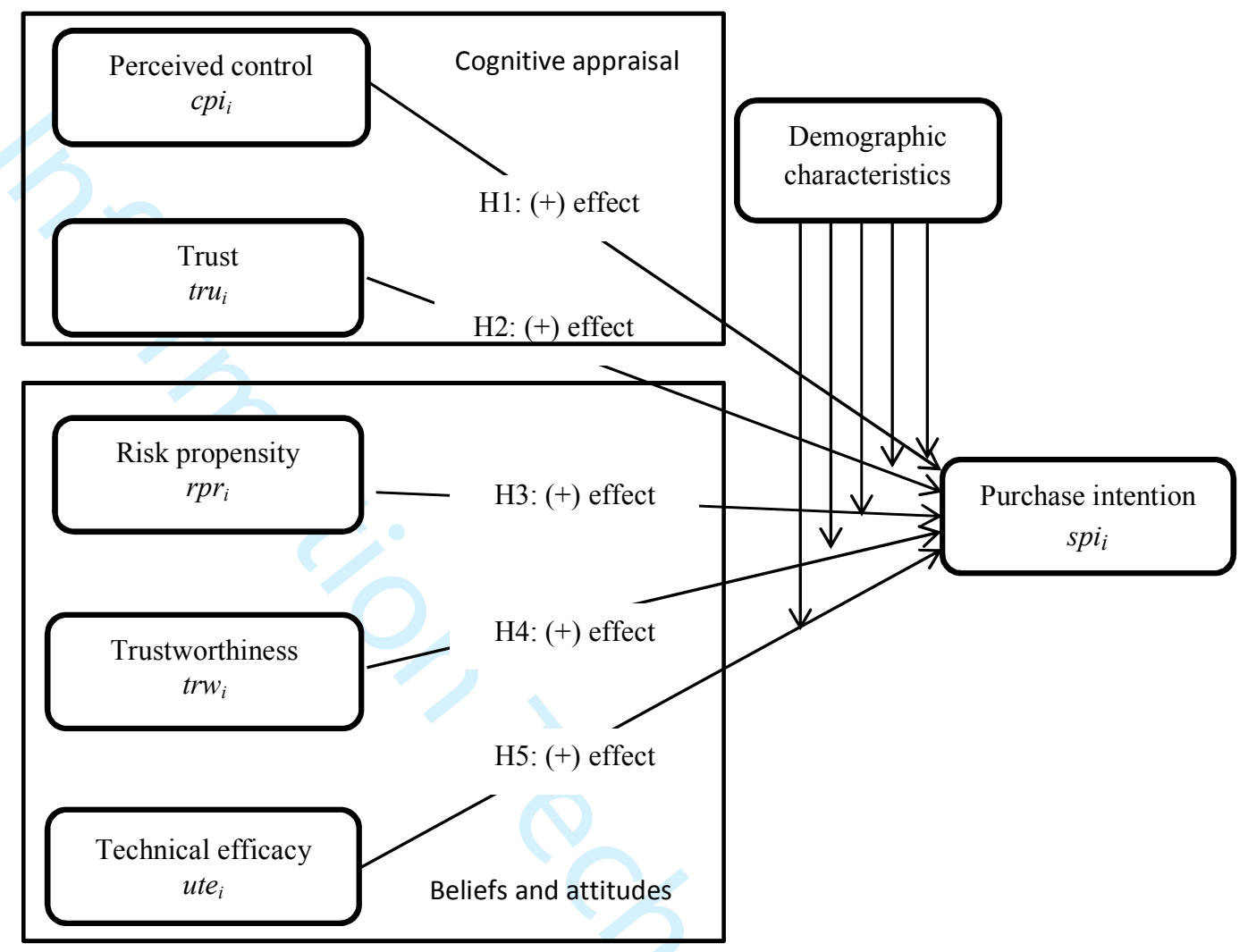


Table 1. Demographics profile.

\begin{tabular}{|l|r|r|}
\hline & Frequency & \multicolumn{2}{|c|}{ Percent } \\
\hline Gender & & 63.2 \\
\hline Female & 325 & 36.8 \\
\hline Male & 189 & \\
\hline Age & & 41.1 \\
\hline $18-28$ & 211 & 27.2 \\
\hline $29-38$ & 140 & 16.7 \\
\hline $39-48$ & 86 & 11.7 \\
\hline $49-58$ & 60 & 3.3 \\
\hline $59-68$ & 17 & 4.1 \\
\hline Education & & 6.6 \\
\hline Lower Secondary Level & 21 & 37.2 \\
\hline Upper Secondary Level & 34 & 34.8 \\
\hline Bachelor's Degree & 191 & 8.9 \\
\hline Master's Degree & 179 & 8.4 \\
\hline Doctoral Degree & 46 & 100 \\
\hline Other & 43 & 514 \\
\hline Total & & \\
\hline
\end{tabular}


Table 2. Cronbach's alpha and Composite reliability

\begin{tabular}{|l|c|c|c|}
\hline & Cronbach's alpha & Composite Reliability & Average Variance Extracted \\
\hline Purchase Intention $s p i$ & 0.899 & 0.928 & 0.729 \\
\hline Risk Propensity $r p r$ & 0.792 & 0.836 & 0.634 \\
\hline Technical Efficacy $u t e$ & 0.916 & 0.938 & 0.792 \\
\hline Trust $t r u$ & 0.738 & 0.845 & 0.65 \\
\hline Trustworthiness of the SNS $t r w$ & 0.918 & 0.949 & 0.86 \\
\hline Perceived control $c p i$ & 0.896 & 0.927 & 0.762 \\
\hline
\end{tabular}

Cronbach's alpha and Composite reliability should be above 0.7. The Average Variance Extracted should exceed 0.5

Table 3 Discriminant validity

\begin{tabular}{|l|c|c|c|c|c|c|}
\hline & $\begin{array}{c}\text { Purchase } \\
\text { Intention }\end{array}$ & $\begin{array}{c}\text { Risk } \\
\text { propensity }\end{array}$ & Technical Efficacy & Trust & Trustworthiness & Perceived control \\
\hline Purchase Intention $s p i$ & $\mathbf{0 . 8 5 4}$ & & & & & \\
\hline Risk Propensity $r p r$ & 0.191 & $\mathbf{0 . 7 9 6}$ & & & & \\
\hline Technical Efficacy $u t e$ & -0.07 & -0.065 & $\mathbf{0 . 8 9}$ & & & \\
\hline Trust $t r u$ & 0.326 & 0.15 & 0.006 & $\mathbf{0 . 8 0 6}$ & & \\
\hline Trustworthiness of the SNS trw & 0.258 & 0.157 & 0.041 & 0.485 & $\mathbf{0 . 9 2 8}$ & \\
\hline Perceived control $c p i$ & 0.245 & 0.134 & -0.062 & 0.439 & 0.36 & $\mathbf{0 . 8 7 3}$ \\
\hline
\end{tabular}

No high correlations between constructs found. We also test for multicollinearity, reporting the Variance Inflation Factors (VIF) along with the regression results 
Table 4. Estimated coefficients.

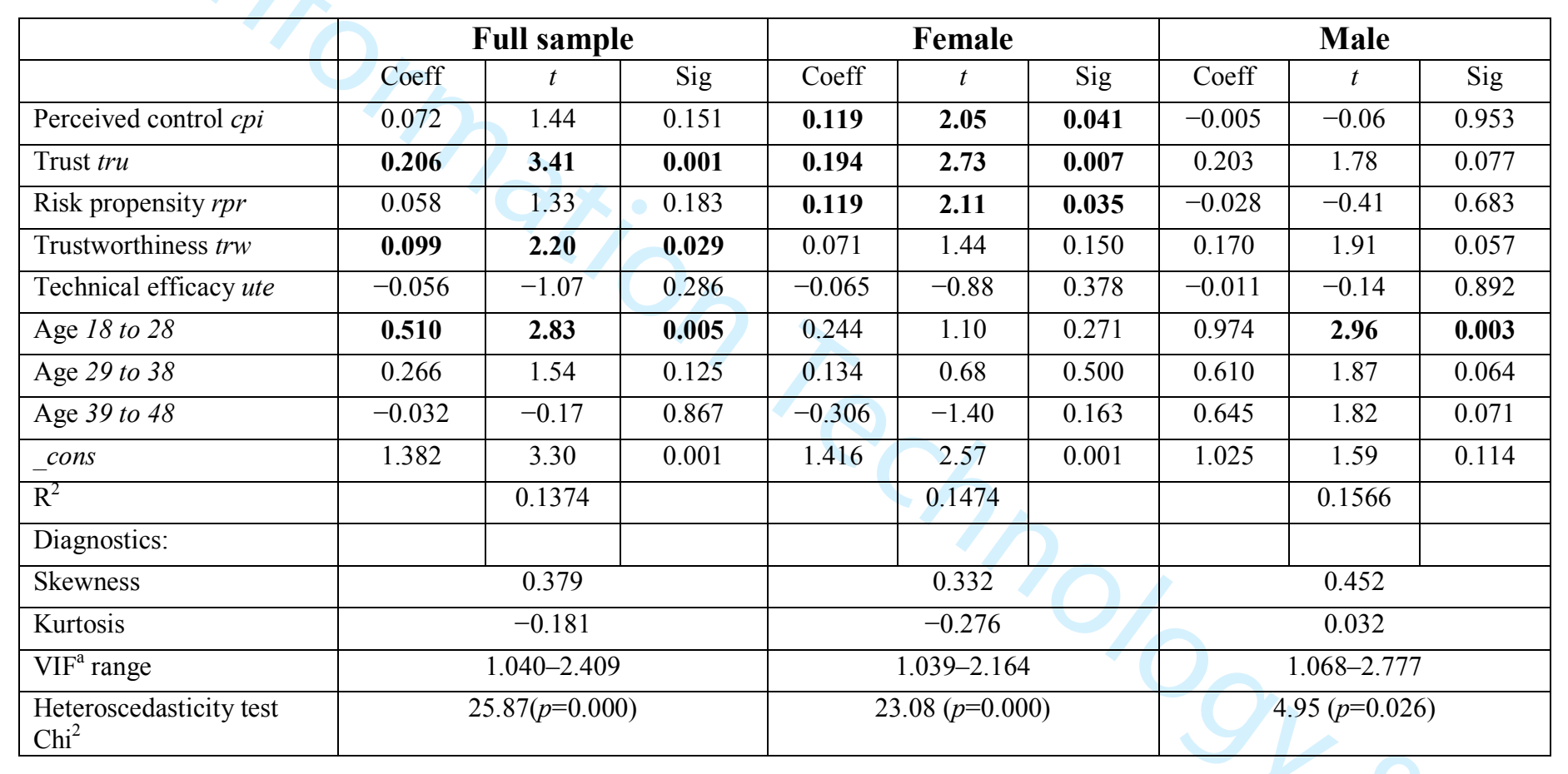


Table 5. Estimated coefficients by age groups and gender.

\begin{tabular}{|c|c|c|c|c|c|c|c|c|c|c|c|c|}
\hline 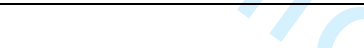 & \multicolumn{3}{|c|}{ Female 18-28 } & \multicolumn{3}{|c|}{ Female 29 and over } & \multicolumn{3}{|c|}{ Male 18-28 } & \multicolumn{3}{|c|}{ Male 29 and over } \\
\hline & Coeff & $t$ & Sig & Coeff & $t$ & Sig & Coeff & $t$ & Sig & Coeff & $t$ & Sig \\
\hline Perceived control $c p i$ & -0.029 & -0.266 & 0.791 & .199 & 2.944 & 0.004 & -.083 & -0.718 & 0.475 & 0.118 & 1.152 & 0.253 \\
\hline Trust tru & 0.219 & 1.585 & 0.116 & .161 & 2.019 & 0.045 & .251 & 1.541 & 0.126 & 0.202 & 1.598 & 0.114 \\
\hline Risk propensity $r p r$ & 0.243 & 2.399 & 0.018 & .032 & .535 & 0.593 & -.064 & -0.595 & 0.553 & -0.032 & -0.389 & 0.698 \\
\hline Trustworthiness trw & 0.157 & 1.357 & 0.178 & .038 & .631 & 0.529 & .147 & 1.142 & 0.256 & 0.195 & 1.910 & 0.060 \\
\hline Technical efficacy ute & -0.030 & -0.246 & 0.806 & -.126 & -1.314 & 0.190 & -.059 & -0.499 & 0.619 & 0.064 & 0.672 & 0.503 \\
\hline _const & 1.149 & 1.380 & 0.171 & 2.013 & 2.782 & 0.006 & 2.561 & 3.001 & 0.003 & 0.647 & 0.916 & 0.363 \\
\hline $\mathrm{R}^{2}$ & & 0.165 & & & 0.122 & & & $0.064^{*}$ & & & 0.188 & \\
\hline \multicolumn{13}{|l|}{ Diagnostics: } \\
\hline Skewness & \multicolumn{3}{|c|}{0.311} & \multicolumn{3}{|c|}{0.365} & \multicolumn{3}{|c|}{0.419} & \multicolumn{3}{|c|}{0.497} \\
\hline Kurtosis & \multicolumn{3}{|c|}{-0.397} & \multicolumn{3}{|c|}{-0.090} & \multicolumn{3}{|c|}{-0.202} & \multicolumn{3}{|c|}{0.210} \\
\hline $\mathrm{VIF}^{\mathrm{a}}$ range & \multicolumn{3}{|c|}{$1.093-1.626$} & \multicolumn{3}{|c|}{$1.025-1.288$} & \multicolumn{3}{|c|}{$1.049-1.506$} & \multicolumn{3}{|c|}{$1.019-1.567$} \\
\hline
\end{tabular}

* Denotes non-significant at the 5\% level

a: Variance Inflation Factor 
Table 6. SNS Constructs exhibit.

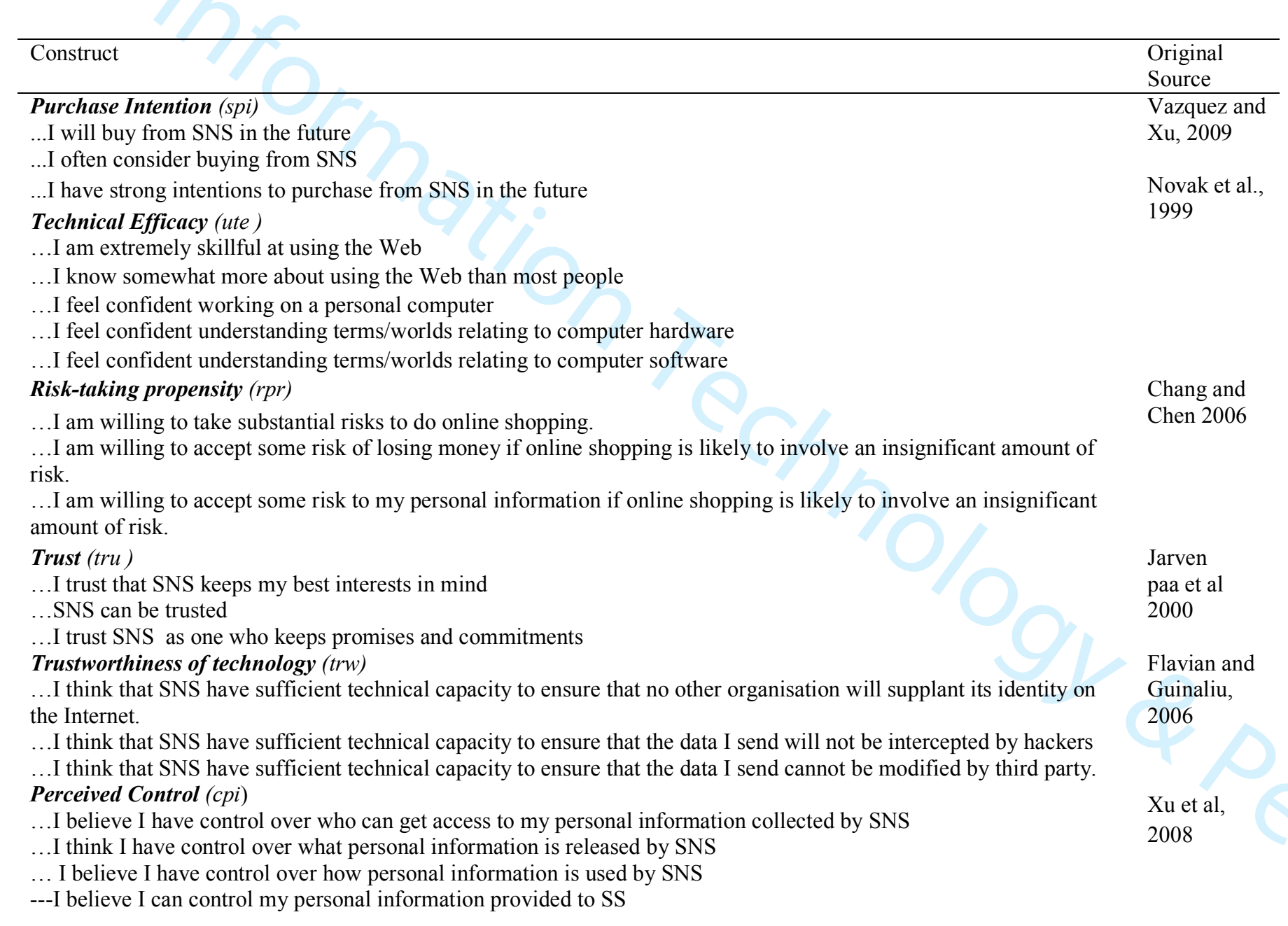


